\title{
Modeling of the aorta artery aneurysms and renal artery stenosis using cardiovascular electronic system Kamran Hassani*1, Mahdi Navidbakhsh ${ }^{\dagger 2}$ and Mostafa Rostami ${ }^{\dagger 3}$
}

Address: ${ }^{1}$ Biomedical Engineering Department, Amirkabir University, Tehran, Iran, ${ }^{2}$ Mechanical Department, Iran University of Science and Technology, Tehran, Iran and ${ }^{3}$ Biomedical Engineering Department, Amirkabir University, Tehran, Iran

Email: Kamran Hassani* - inspect@chagalesh.com; Mahdi Navidbakhsh - mnavid@iust.ac.ir; Mostafa Rostami - rostami@iut.ac.ir

* Corresponding author †Equal contributors

Published: 9 June 2007

BioMedical Engineering OnLine 2007, 6:22 doi:10.1 186//475-925X-6-22
Received: 21 January 2007

Accepted: 9 June 2007

This article is available from: http://www.biomedical-engineering-online.com/content/6/1/22

(C) 2007 Hassani et al; licensee BioMed Central Ltd.

This is an Open Access article distributed under the terms of the Creative Commons Attribution License (http://creativecommons.org/licenses/by/2.0), which permits unrestricted use, distribution, and reproduction in any medium, provided the original work is properly cited.

\begin{abstract}
Background: The aortic aneurysm is a dilatation of the aortic wall which occurs in the saccular and fusiform types. The aortic aneurysms can rupture, if left untreated. The renal stenosis occurs when the flow of blood from the arteries leading to the kidneys is constricted by atherosclerotic plaque. This narrowing may lead to the renal failure. Previous works have shown that, modelling is a useful tool for understanding of cardiovascular system functioning and pathophysiology of the system. The present study is concerned with the modelling of aortic aneurysms and renal artery stenosis using the cardiovascular electronic system.
\end{abstract}

Methods: The geometrical models of the aortic aneurysms and renal artery stenosis, with different rates, were constructed based on the original anatomical data. The pressure drop of each section due to the aneurysms or stenosis was computed by means of computational fluid dynamics method. The compliance of each section with the aneurysms or stenosis is also calculated using the mathematical method. An electrical system representing the cardiovascular circulation was used to study the effects of these pressure drops and the compliance variations on this system.

Results: The results showed the decreasing of pressure along the aorta and renal arteries lengths, due to the aneurysms and stenosis, at the peak systole. The mathematical method demonstrated that compliances of the aorta sections and renal increased with the expansion rate of the aneurysms and stenosis. The results of the modelling, such as electrical pressure graphs, exhibited the features of the pathologies such as hypertension and were compared with the relevant experimental data.

Conclusion: We conclude from the study that the aortic aneurysms as well as renal artery stenosis may be the most important determinant of the arteries rupture and failure. Furthermore, these pathologies play important rules in increase of the cardiovascular pulse pressure which leads to the hypertension.

\section{Background}

The aortic aneurysm is a disease, which is defined as focal or diffuse dilatation of the aorta. Most of the aorta aneu- rysms are fusiform (concentric radial dilatation) but infrequently may be saccular (eccentric radial dilatation). The abdominal aorta aneurysm is the most common form of 
the aneurismal disease. Less commonly patients may present with the thoracic aorta aneurysms. The aorta aneurysms have primarily been studied by Long [1] and Morris [2] who investigated the compliance of aortic aneurysms and observed the effects of the pathology. More recent studies have used the clinical data to investigate the aortic aneurysms [3-5].

On the other hand, the cardiovascular disease is very common in the patients with the renal artery stenosis. The two main causes of the renal artery stenosis are atherosclerosis and fibro muscular disease. Woolfson [6], Bude [7], Nawaz khan [8] and Coen [9] have shown that the renal artery stenosis may lead to the hypertension, fluid retention, progressive renal failure and flash pulmonary edema. In this study, we have taken a slightly different approach to the modelling of the cardiovascular disorders and tried to exhibit the effects of the aortic aneurysms and renal artery stenosis on the cardiovascular system using the combination of the haemodynamic and electrical parameters. The principal goal of this study is to present the possibility of modelling the cardiovascular pathologies, such as the aortic aneurysms or renal artery stenosis, using an electronic circuit representing the whole cardiovascular system. To realize this aim, this study includes the following four components:

1) A brief review of the electronic cardiovascular system which has been previously described in detail [10].

2) The computational fluid dynamics method which has been used to compute the pressure drops due to the pathologies.

3) The mathematical method which has been used to calculate the variations of the compliance due to the pathologies.

4) The study of the effects of the pathologies using the electronic cardiovascular system and investigating the cases.

The obtained results have been compared with the relevant clinical data to determine whether our modelling method has been able to present the effects of the pathologies appropriately.

\section{Methods}

The electronic cardiovascular system review

The lumped parameter model of the cardiovascular system including the block diagram and the specifications of each element is presented in Figure 1 and Table 1 . The equivalent model of the system including the pulsatile heart and the arterial tree is illustrated in Figure 2 in terms of its electrical circuit analog, in which voltage(volt) is

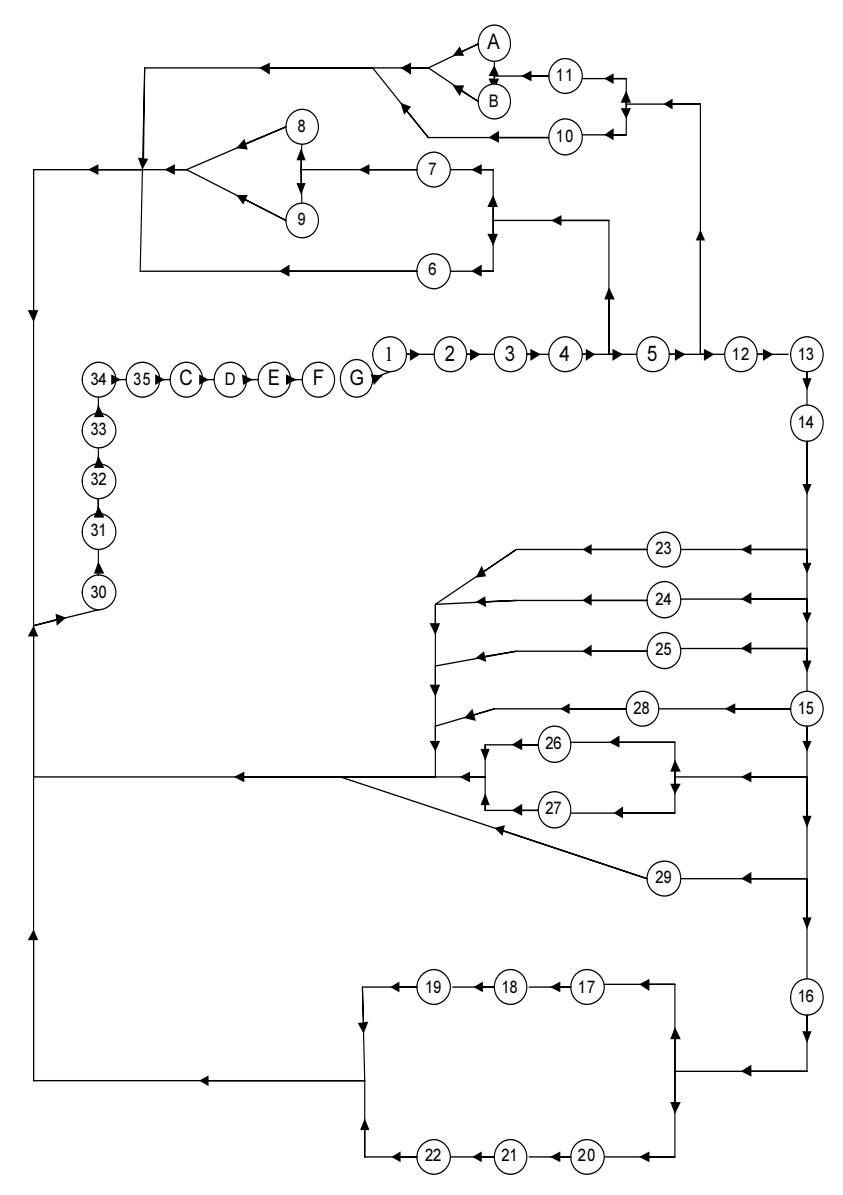

Figure I

The block diagram and specifications of the system's elements. The block diagram of the cardiovascular system.

analogous to pressure $(1 \mathrm{mmHg})$, capacitance $(1000 \mu \mathrm{F})$, to compliance $(1 \mathrm{ml} / \mathrm{Pa})$, resistance $(1 \mathrm{k} \Omega)$, to resistance $(1$ Pa.s/ml)and inductance $(1 \mu \mathrm{H})$ to inertance $\left(1 \mathrm{~Pa}^{2} \mathrm{~s}^{2} / \mathrm{ml}\right)$. The electrical model consists of forty two elements which represent the left and right ventricles, systemic arteries and veins, and pulmonary arteries and veins. Each element consists of a conduit for viscous blood flow, which is characterized by a linear resistance and a volume storage element, which is characterized by a linear capacitor. The inertance of each element is characterized by a linear inducer. The reference pressure is atmosphere pressure (or ground) for the circuit. The energy of systolic contraction is modeled by superposition of three voltage suppliers and two ideal diodes. The voltage suppliers vary periodically over time and are responsible for driving the flow of blood in both left and right ventricles. The four ideal diodes represent the ventricular inflow and outflow valves and ensure unidirectional blood flow; furthermore the model works at the frequency of $1 \mathrm{~Hz}$. We have demonstrated [10] that this model behaves reasonably in terms 
Table I: The electrical specifications of each element. The electrical characteristics of the elements of the system with reference to the block diagram of Figure $I$.

\begin{tabular}{clccc}
\hline ITEM & \multicolumn{1}{c}{ DESCRIPTION } & $\mathrm{R}(\mathrm{k} \Omega)$ & $\mathrm{L}(\mu \mathrm{H})$ & $\mathrm{C}(\mu \mathrm{F})$ \\
\hline I & Left Atrium & 0.5 & 0.1 & 101 \\
2 & Left Ventricle & 0.5 & 0.1 & 25 \\
3 & Ascending Aorta & 7.6 & 0.133 & 0.918 \\
4 & Aortic Arch I & $0.01 \mathrm{I}$ & 0.144 & 0.262 \\
5 & Aortic Arch 2 & 0.0265 & 0.245 & 0.489 \\
6 & Right Subclavin II & 14.118 & 18.61 & 0.489 \\
7 & Right Carotid & 8.14 & 9.3 & 0.167 \\
8 & Right int Carotid & 159.8 & 40.4 & 0.01277 \\
9 & Right ext Carotid & 160.7 & 40.6 & 0.0137 \\
I0 & Left Subclavin II & 14.118 & 18.61 & 0.489 \\
II & Left Carotid & 9.89 & 10.93 & 0.197 \\
A & Left int Carotid & 159.8 & 40.4 & 0.01277 \\
B & Left ext Carotid & 160.72 & 40.6 & 0.0137 \\
I2 & Thoracic Aorta I & 0.046 & 0.374 & 0.556 \\
I3 & Thoracic Aorta 2 & 0.446 & 1.642 & 0.376 \\
I4 & Abdominal Aorta I & 0.419 & 0.749 & 0.1933 \\
I5 & Abdominal Aorta 2 & 0.882 & 2.439 & 0.353 \\
I6 & Abdominal Aorta 3 & 0.1218 & 0.2661 & 0.0254 \\
I7 & Left Common Iliac & 2.867 & 3.135 & 0.0557 \\
I8 & Left External lliac & 12.23 & 10.1 & 0.0524 \\
I9 & Left Femoral & 87.74 & 47.533 & 0.0906 \\
20 & Right Common Iliac & 2.867 & 3.135 & 0.0577 \\
21 & Right External Iliac & 12.23 & 10.1 & 0.0524 \\
22 & Right Femoral & 87.74 & 47.533 & 0.0906 \\
23 & Hepatic & 25.11 & 9.815 & 0.0168 \\
24 & Oastric & 60.28 & 15.77 & 0.0108 \\
25 & Splenic & 9.817 & 5.996 & 0.0285 \\
26 & Left Renal & 6.24 & 3.4072 & 0.0125 \\
27 & Right Renal & 6.24 & 3.4072 & 0.0125 \\
28 & Superior Mesenteric & 1.468 & 2.244 & 0.0829 \\
29 & Inferior Mesenteric & 68 & 14.058 & 0.00561 \\
30 & Arterioles & 72 & 1 & 1.4 \\
31 & Capillaries & 48 & 1 & 71 \\
32 & Vein I & 9 & - & 210 \\
33 & Vein 2 & 1 & 0.1 & 450 \\
34 & Right Atrium & 0.5 & 0.1 & 216.45 \\
35 & Right Ventricle & 0.5 & 0.1 & 150 \\
C & Pulmonary Artery I & 1 & 0.1 & 1 \\
D & Pulmonary Artery 2 & 4 & - & 1 \\
E & Pulmonary Artery 3 & 8 & - & 3 \\
F & Pulmonary Vein I & 3 & - & 27 \\
G & Pulmonary Vein 2 & 1 & 0.1 & 10 \\
& & & &
\end{tabular}

of pulsatile waveforms and properties of the systemic circulation.

\section{The applications of computational fluid dynamics method (CFD) to the modelling}

I) The aorta aneurysms

The geometrical model of each aorta section with the aneurysm was made according to the anatomical data [11] and illustrated in Figure 3. The locations of the hypothetical aneurysms including fusiform and saccular, were placed in the middle of the studied sections. In our other study [12] including 100 patients, we observed that the saccular aneurysms occur mostly in the abdominal aorta and rarely in the thoracic aorta where the fusiform aneurysms occur both in the abdominal and thoracic aorta sections. The geometry of the saccular aneurysm is assumed by

$$
r(x)=a x^{2}+b x+c
$$

The geometry of the fusiform aneurysm is assumed by

$$
r(x)=a \sin \pi \cdot x+b
$$

The a, b and c coefficients can be easily calculated by the geometrical model of each aorta section, considering the different aneurysm expansion rates, according to Figure 3. In this geometry, (R) is the tube radius of the unobstructed part, (L) is the total length of the tube and (D) is the value of the maximum posterior displacement of the aneurismal wall which is determined by expanding the tube radius $(\mathrm{R})$ with the following rate

$$
D=R+n
$$

The parameter (n) is $20 \% \mathrm{R}, 40 \% \mathrm{R}, 50 \% \mathrm{R}, 70 \% \mathrm{R}$ and $90 \% \mathrm{R}$ representing the aneurysm expansion rate. It has been assumed that blood flow is represented by a laminar, incompressible, ideal and Newtonian fluid of constant viscosity, and density. The appropriate experimental equation for blood flow subject to the aorta artery has been expressed by Womersley [13] as a sinusoidal function, with frequency of $1 \mathrm{~Hz}$,

$$
\begin{gathered}
Q=1.05+2.407 \operatorname{Sin}(6.283 t+0.552)+ \\
2.324 \operatorname{Sin}(12.566 t-1.096)- \\
0.921 \operatorname{Sin}(18.849 t+0.7384)- \\
0.398 \operatorname{Sin}(25.132 t-0.082)
\end{gathered}
$$

The parameter $(\mathrm{Q})$ is the volumetric flow rate $(\mathrm{ml} / \mathrm{s})$. The velocity (U) at any given cross section of the aorta artery with radius $(\mathrm{R})$ can be written as

$$
U=\frac{Q}{\pi \cdot R^{2}}
$$

Gambit software can automatically generate a mesh for any geometry. The uniform meshes were used for each of the aorta sections with the aneurysms. The quadrilateral and mappable elements were used for the fluid domain. We have used the computational fluid dynamics method, fluent code, to compute the pressure drops of the sections with the aneurysms. The velocity waveform, expressed by equation (5) was applied at the inlet boundary of each studied section. Blood properties chosen were viscosity of 0.0035 (Pa.s) and density of $1050\left(\mathrm{~kg} / \mathrm{m}^{3}\right)$. The outlet was 


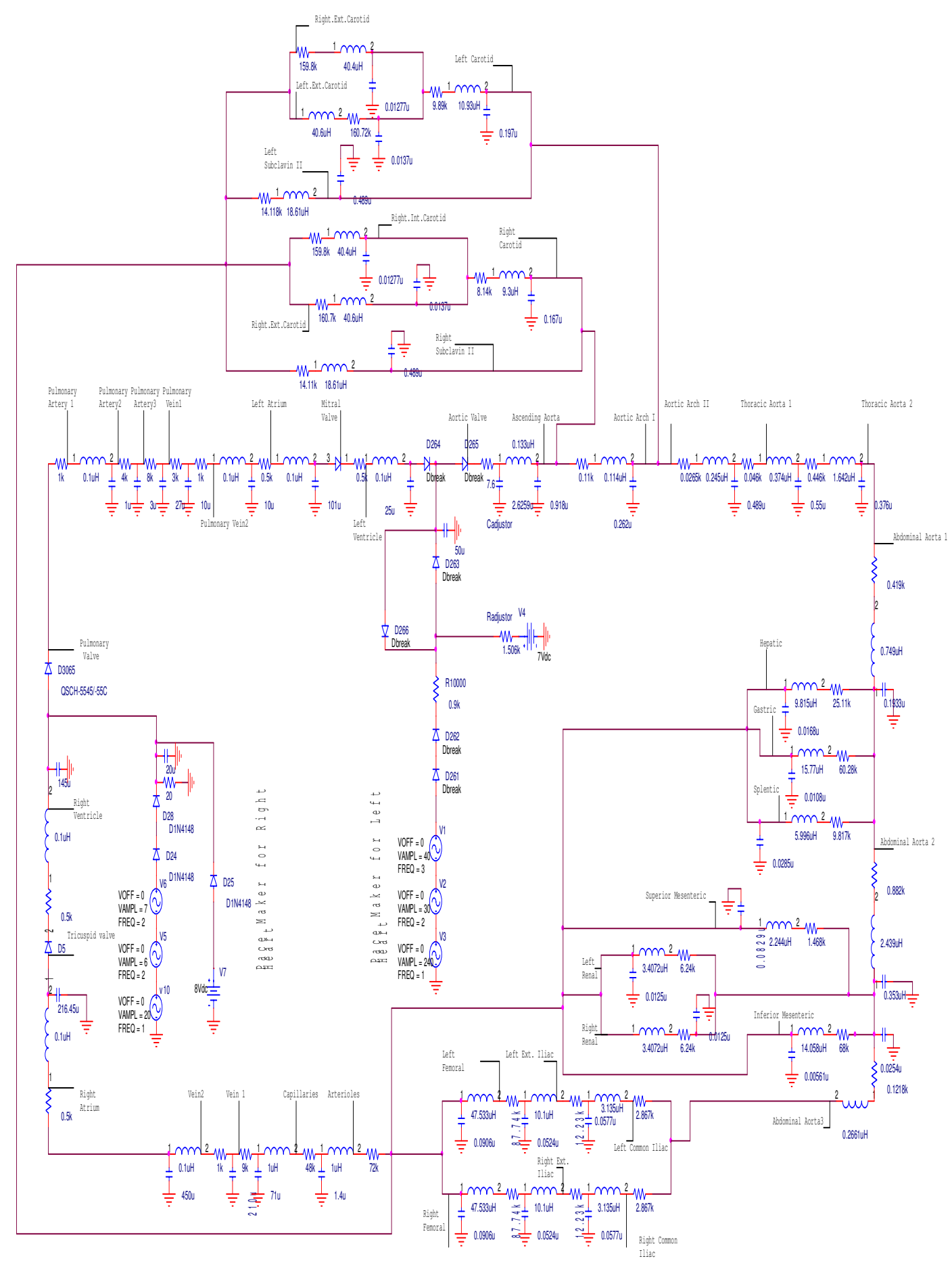

Figure 2

Electrical circuit of the cardiovascular system. The electrical circuit of the cardiovascular system including 42 elements. Each element is named on the circuit. 

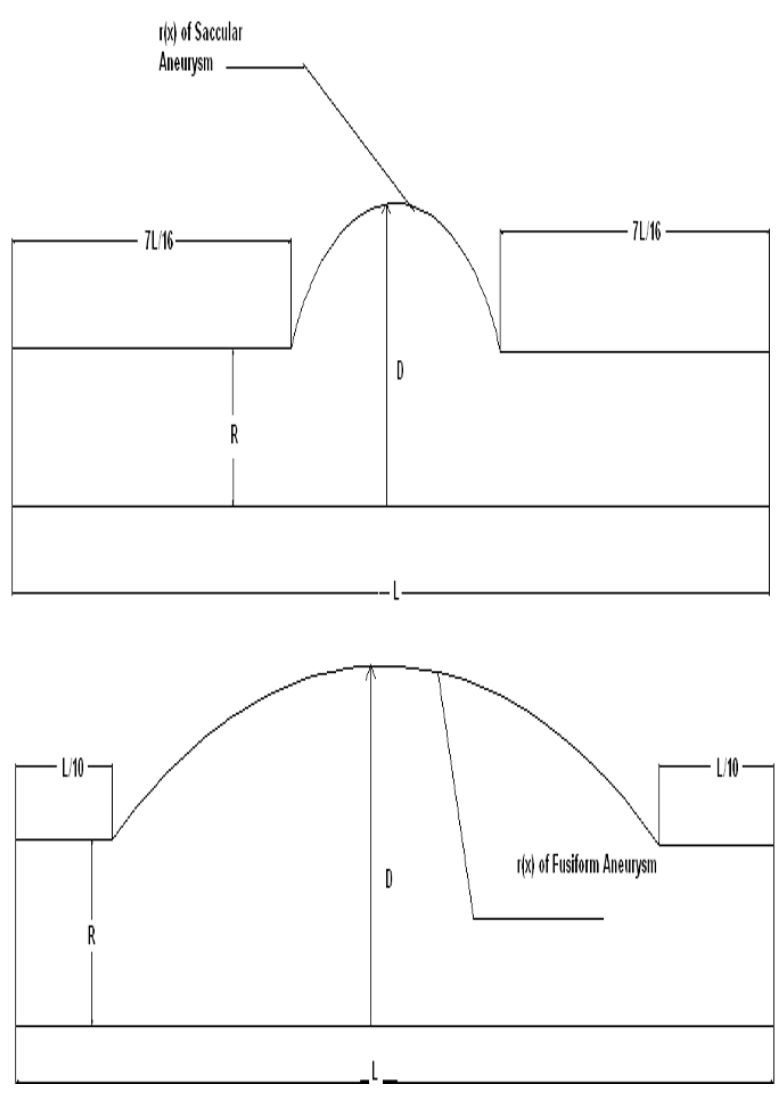

Figure 3

The geometrical model of the aortic aneurysms. The geometry of aortic saccular aneurysm(above) and the geometry of fusiform aneurysm(under). Both aneurysms are located in the center of the artery.

assumed as the zero pressure state and the inlet pressure was computed by the code. The solution method was 2D,

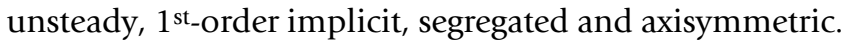
The time step size was 0.1 (s) and typically 10-20 iterations were required per time steps. The simulation reached nearly steady state oscillation after the second cycle. The pressure difference between the inside and outside of each aorta section was recorded.

\section{2) The renal artery stenosis}

The geometrical model of the renal artery with the stenosis was made using the anatomical data [11] and illustrated in Figure 3. The renal artery stenosis due to arterial dysplasia generally affects the middle and distal renal artery in the patients [8], therefore we located the hypothetical stenosis in the middle of the artery. The geometry of the renal artery stenosis is assumed by

$$
r(x)=a x^{2}+b x+c
$$

The $\mathrm{a}$, b and c coefficients were calculated by geometrical model of the artery according to Figure 4. In this geometry, (R) is the tube radius of the normal part; (L) is the total length of the tube and (D) is the value of the maximum interior displacement of the wall with the stenosis and determined by narrowing the tube radius ( $R$ ) with the following rate

$$
D=R-n
$$

The parameter $(\mathrm{n})$ is $20 \% \mathrm{R}, 40 \% \mathrm{R}, 50 \% \mathrm{R}, 70 \% \mathrm{R}$ and $90 \% \mathrm{R}$ representing the stenosis narrowing rate. The peak systolic velocity in the renal artery averages $120 \pm 12 \mathrm{~cm} / \mathrm{s}$ ) [8]. We assumed a simple sinusoidal function for blood velocity subject to the renal artery which is given by

$$
V=1.2 \operatorname{Sin}(6.283 t+0.552)
$$

The parameter $(\mathrm{V})$ is according to $(\mathrm{m} / \mathrm{s})$ unit and the frequency of the equation is $1 \mathrm{~Hz}$. The pressure difference between the inside and the outside of the renal artery with different stenosis rates was computed and recorded using the same method which was described above in section A.

\section{The applications of the mathematical method to the modelling}

The compliances of the aortic aneurysms and the renal artery stenosis were computed by the mathematical method. The compliance of an elastic vessel is defined by [14]

$$
C=\frac{3 \pi \cdot R^{3} \cdot Z}{2 E h}
$$

The parameter $(R)$ is the radius of the vessel, $(Z)$ is the length of the vessel, (h) is the thickness of the vessel, and (E) is the elastic module of the vessel. The normal compliances of the aorta artery sections and the renal artery were computed by equation (9). In order to calculate the saccular aneurysms, we substituted equation (1) into equation (9) to give

$$
d C=\frac{3 \pi \cdot\left(a x^{2}+b x+c\right)^{3} d x}{2 E h}
$$

Integrating equation (10) using the geometry of Figure 2 and the condition $\mathrm{X}_{0}=7 \mathrm{~L} / 16, \mathrm{X}_{1}=9 \mathrm{~L} / 16$, we have

$$
C_{\text {saccular aneurysm }}=\int_{X 0}^{X 1} \frac{3 \pi \cdot\left(a x^{2}+b x+c\right)^{3} d x}{2 E h}
$$




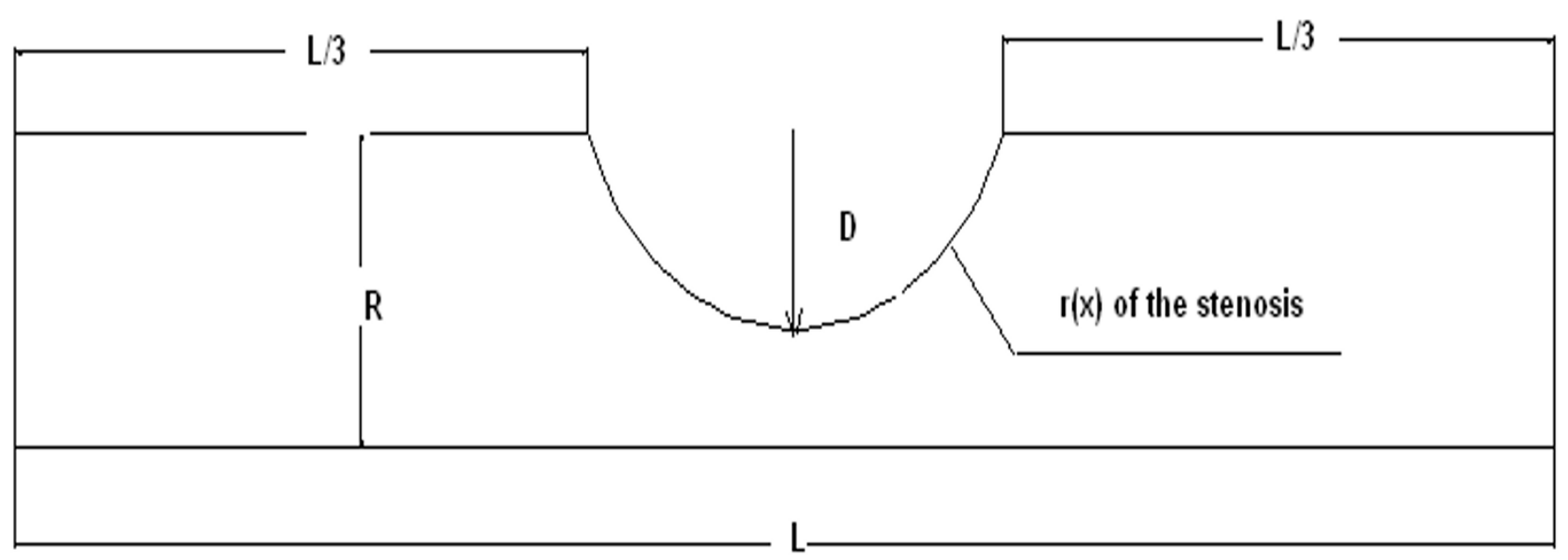

Figure 4

The geometrical model of the renal stenosis. The geometry of renal stenosis which is located in the centre.

We performed the similar mathematical method for the fusiform aneurysms and got

$$
C_{\text {Fusiform aneurysm }}=\int_{X 0}^{X 1} \frac{3 \pi \cdot(a \sin \pi \cdot x+b)^{3} d x}{2 E h}
$$

Where $\mathrm{X}_{0}=\mathrm{L} / 10$ and $\mathrm{X}_{1}=2 \mathrm{~L} / 3$, according to the geometry in Figure 3. The total compliance of each aorta artery section with the saccular or fusiform aneurysms is given by

$$
C_{\text {total }}=C_{\text {normal parts }}+C_{\text {aneurysmal parts }}
$$

Again, the compliance of the unobstructed parts was calculated using equation (9). The compliance of the renal stenosis is determined with the same mathematical method and given by

$$
C_{\text {renal stenosis }}=\int_{X 0}^{X 1} \frac{3 \pi \cdot\left(a x^{2}+b x+c\right)^{3} d x}{2 E h}
$$

Where $\mathrm{X}_{0}=\mathrm{L} / 3$ and $\mathrm{X}_{1}=2 \mathrm{~L} / 3$ in accordance with the geometry in Figure 4 . The total compliance of the renal artery with the stenosis is also given by

$$
C_{\text {total }}=C_{\text {normal parts }}+C_{\text {renal stenosis }}
$$

The applications of the cardiovascular electronic system to the modelling

The electronic circuit of the aorta artery, shown in Figure 2 , consists of six resistors, capacitors and inducers. The computed pressure drop and the compliance of each aorta section with the aneurysms were converted to their electrical counterparts including resistance and capacitance. These new values of the resistances and the capacitances were applied to the relating part on the aorta circuit. The whole cardiovascular electronic system was run to the time, $100 \mathrm{~s}$, and the results were obtained and recorded. The similar method was used to study the effects of the renal stenosis on the electronic cardiovascular system.

\section{Results}

\section{I) The aorta artery aneurysms}

Table 2 shows the results of the modeling including the pressure drops, at peak systole, and the compliances of different aorta sections with the aneurysms. The pressure wave form at the inlet of the abdominal III aorta, with $90 \%$ expansion rate of the saccular aneurysm, is presented in Figure 5. We see the pressure rises above zero (97.6 Pa) at the peak systole and reaches a minimum value $(-110$ $\mathrm{Pa})$ at the max reverse flow. A negative pressure shows the decelerative phase of the aortic flow. The pressure contour of this section is also presented in Figure 6 . The pressure decreases along the artery length at the peak systole. The similar pressure contour is presented for thoracic I aorta with 50\% expansion rate of the fusiform aneurysm in Figure 7. We studied the effects of the aorta aneurysms on the electronic circuit of the cardiovascular system as well. Figure 8 presents the diastole/systole pressure graph of the abdominal I aorta with $20 \%$ expansion rate of the saccular aneurysm. The pressure waveform varies between 55 $\mathrm{mmHg}$ (volt) to 155 representing diastolic and systolic pressure values. This figure also shows the variation of the pressure during the cardiac cycle for the abdominal II aorta with $40 \%$ expansion rate of the fusiform aneurysm.

\section{2) The renal artery stenosis}

Table 3 shows the results of the modeling including the pressure drops, at peak systole, and the compliances of the renal artery with different rate of the stenosis. Figure 9 
Table 2: The results of modelling for the aortic aneurysms. The values of pressure drops (obtained by CFD), compliances (obtained by the mathematics) and final Diastolic/Systolic pressures of different sections of the aorta with the aneurysms (obtained by electrical system). Please note that the values are approximate.

\begin{tabular}{|c|c|c|c|c|c|c|}
\hline $\begin{array}{c}\text { Abdominal I } \\
(\mathrm{Dia}=12.2 \mathrm{~mm} \\
\mathrm{L}=63 \mathrm{~mm})\end{array}$ & $\begin{array}{c}\Delta \mathrm{P}_{\text {systole }}(\mathrm{pa}) \\
\text { (fusiform) }\end{array}$ & $\begin{array}{c}\mathrm{C}_{\text {aneurysm }}(\mathrm{ml} / \mathrm{kpa}) \\
\text { (fusiform) }\end{array}$ & $\begin{array}{c}\Delta \mathrm{P}_{\text {systole }}(\mathrm{pa}) \\
\text { (saccular) }\end{array}$ & $\mathrm{C}_{\text {(saccular) }}^{\mathrm{C}_{\text {aneurysm }}(\mathrm{ml} / \mathrm{kpa})}$ & $\begin{array}{l}\text { Diastol/Systole } \\
\text { Pressure }(\mathrm{mmHg}) \\
\text { (fusiform) }\end{array}$ & $\begin{array}{l}\text { Diastol/Systole } \\
\text { Pressure }(\mathrm{mmH}) \\
\text { (Saccular) }\end{array}$ \\
\hline $20 \%$ Aneurysm & 70.34 & 0.212 & 84.3 & 0.1985 & $55-150$ & $55-155$ \\
\hline $40 \%$ Aneurysm & 69.9 & 0.302 & 79 & 0.2038 & $55.2-149.7$ & $55.3-154$ \\
\hline $50 \%$ Aneurysm & 69 & 0.36 & 76.4 & 0.22836 & $56-149.2$ & $55.2-153$ \\
\hline 70\% Aneurysm & 65 & 0.504 & 74.6 & 0.28677 & $56.8-148.7$ & $56.1-152.1$ \\
\hline $90 \%$ Aneurysm & 59.5 & 0.692 & 74.1 & 0.3587 & $58-148$ & $56.8-|5|$ \\
\hline $\begin{array}{c}\text { Abdominal II } \\
\text { (Dia }=11.7 \mathrm{~mm} \\
\mathrm{~L}=116 \mathrm{~mm})\end{array}$ & $\begin{array}{c}\Delta \mathrm{P}_{\text {systole }}(\mathrm{pa}) \\
\text { (fusiform) }\end{array}$ & $\begin{array}{c}\mathrm{C}_{\text {aneurysm }}(\mathrm{ml} / \mathrm{kpa}) \\
\text { (fusiform) }\end{array}$ & $\begin{array}{c}\Delta \mathrm{P}_{\text {systole }}(\mathrm{pa}) \\
\text { (saccular) }\end{array}$ & $\underset{\text { (saccular) }}{\mathrm{C}_{\text {aneurysm }}(\mathrm{ml} / \mathrm{kpa})}$ & $\begin{array}{l}\text { Diastol/Systole } \\
\text { Pressure }(\mathrm{mmHg}) \\
\text { (fusiform) }\end{array}$ & $\begin{array}{l}\text { Diastol/Systole } \\
\text { Pressure }(\mathrm{mmHg}) \\
\text { (Saccular) }\end{array}$ \\
\hline $20 \%$ Aneurysm & 83.4 & 0.4785 & 87.9 & 0.4454 & $58-158$ & $57-156$ \\
\hline $40 \%$ Aneurysm & 75.73 & 0.805 & 85 & 0.5678 & $60-155$ & $59-155$ \\
\hline $50 \%$ Aneurysm & 74.8 & 1.0 & 84.2 & 0.6438 & $62-152$ & $60-154$ \\
\hline 70\% Aneurysm & 62.4 & 1.385 & 83 & 0.745 & $64-148$ & $61.5-152$ \\
\hline $90 \%$ Aneurysm & 61.5 & 2.55 & 82.1 & 1.0625 & $70-147$ & $63-150$ \\
\hline $\begin{array}{c}\text { Abdominal III } \\
(\text { Dia }=10.4 \mathrm{~mm} \\
L=10 \mathrm{~mm})\end{array}$ & $\begin{array}{c}\Delta \mathrm{P}_{\text {systole }}(\mathrm{pa}) \\
\text { (fusiform) }\end{array}$ & $\begin{array}{c}\mathrm{C}_{\text {aneurysm }}(\mathrm{ml} / \mathrm{kpa}) \\
\text { (fusiform) }\end{array}$ & $\begin{array}{c}\Delta \mathrm{P}_{\text {systole }}(\mathrm{pa}) \\
\text { (saccular) }\end{array}$ & $\begin{array}{c}\mathrm{C}_{\text {aneurysm }}(\mathrm{ml} / \mathrm{kpa}) \\
\text { (saccular) }\end{array}$ & $\begin{array}{l}\text { Diastol/Systole } \\
\text { Pressure }(\mathrm{mmHg}) \\
\text { (fusiform) }\end{array}$ & $\begin{array}{l}\text { Diastol/Systole } \\
\text { Pressure }(\mathrm{mmHg}) \\
\text { (Saccular) }\end{array}$ \\
\hline $20 \%$ Aneurysm & 70.4 & 0.225 & 114 & 0.03184 & $55-|5|$ & $55-163$ \\
\hline $40 \%$ Aneurysm & 69.6 & 0.3099 & 110 & 0.0406 & $54-150$ & $56-161$ \\
\hline $50 \%$ Aneurysm & 69.1 & 0.362 & 105 & 0.04603 & $53.8-149.7$ & $57-160$ \\
\hline $70 \%$ Aneurysm & 64 & 0.489 & 100.8 & 0.0592 & $52-148$ & $59-159.2$ \\
\hline $90 \%$ Aneurysm & 58.37 & 0.65 & 97.6 & 0.07605 & $55-146$ & $60-158.3$ \\
\hline $\begin{array}{l}\text { Thoracic I } \\
(\text { Dia = } 20 \mathrm{~mm} \\
\mathrm{L}=52 \mathrm{~mm})\end{array}$ & $\begin{array}{c}\Delta \mathrm{P}_{\text {systole }}(\mathrm{pa}) \\
\text { (fusiform) }\end{array}$ & $\begin{array}{c}\mathrm{C}_{\text {aneurysm }}(\mathrm{ml} / \mathrm{kpa}) \\
\text { (fusiform) }\end{array}$ & $\begin{array}{c}\Delta \mathrm{P}_{\text {systole }}(\mathrm{pa}) \\
\text { (saccular) }\end{array}$ & $\underset{\text { (saccular) }}{\mathrm{C}_{\text {aneurysm }}(\mathrm{ml} / \mathrm{kpa})}$ & $\begin{array}{l}\text { Diastol/Systole } \\
\text { Pressure }(\mathrm{mmHg}) \\
\text { (fusiform) }\end{array}$ & $\begin{array}{l}\text { Diastol/Systole } \\
\text { Pressure }(\mathrm{mmHg} \text { ) } \\
\text { (Saccular) }\end{array}$ \\
\hline $20 \%$ Aneurysm & 26.2 & 0.61475 & - & - & $53-135$ & - \\
\hline $40 \%$ Aneurysm & 23.4 & 0.846 & - & - & $54-133$ & - \\
\hline $50 \%$ Aneurysm & 21.9 & 0.9915 & - & - & $56-132.5$ & - \\
\hline $70 \%$ Aneurysm & 21.5 & 1.347 & - & - & $56.5-132$ & - \\
\hline $90 \%$ Aneurysm & 20.66 & 1.7984 & - & - & $59-130$ & - \\
\hline $\begin{array}{c}\text { Thoracic II } \\
\text { (Dia = I } 3.5 \mathrm{~mm}, \\
\mathrm{~L}=104 \mathrm{~mm} \text { ) }\end{array}$ & $\begin{array}{c}\Delta \mathrm{P}_{\text {systole }}(\mathrm{pa}) \\
\text { (fusiform) }\end{array}$ & $\begin{array}{c}\mathrm{C}_{\text {aneurysm }}(\mathrm{ml} / \mathrm{kpa}) \\
\text { (fusiform) }\end{array}$ & $\begin{array}{c}\Delta \mathrm{P}_{\text {systole }}(\mathrm{pa}) \\
\text { (saccular) }\end{array}$ & $\underset{\text { (saccular) }}{\mathrm{C}_{\text {aneurysm }}(\mathrm{ml} / \mathrm{kpa})}$ & $\begin{array}{l}\text { Diastol/Systole } \\
\text { Pressure }(\mathrm{mmHg}) \\
\text { (fusiform) }\end{array}$ & $\begin{array}{l}\text { Diastol/Systole } \\
\text { Pressure } \\
\text { (Saccular) }\end{array}$ \\
\hline $20 \%$ Aneurysm & 63.7 & 0.505 & - & - & $57-149$ & - \\
\hline $40 \%$ Aneurysm & 51.05 & 0.918 & - & - & $61-147$ & - \\
\hline $50 \%$ Aneurysm & 50.75 & 1.15 & - & - & $61.8-146.5$ & - \\
\hline $70 \%$ Aneurysm & 44.05 & 1.775 & - & - & $66-143.5$ & - \\
\hline $90 \%$ Aneurysm & 42.2 & 2.6259 & - & - & $68-142$ & - \\
\hline
\end{tabular}

shows the variations of pressure along the renal artery length, with $50 \%$ and $90 \%$ stenosis, at peak systole. The high pressure regions along the artery sections are at the inlet to the middle portion. The effects of the renal stenosis were also studied using the electronic system. The diastole/systole pressure graph of the renal artery, with $50 \%$ stenosis, is presented in Figure 10. The variation of pres- sure waveform is between $85-127 \mathrm{mmHg}$ (volt) during the cardiac cycle.

\section{Discussion}

We have modeled the aorta aneurysms and the renal stenosis by means of the computational fluid dynamics and mathematical methods. The results were shown for differ- 


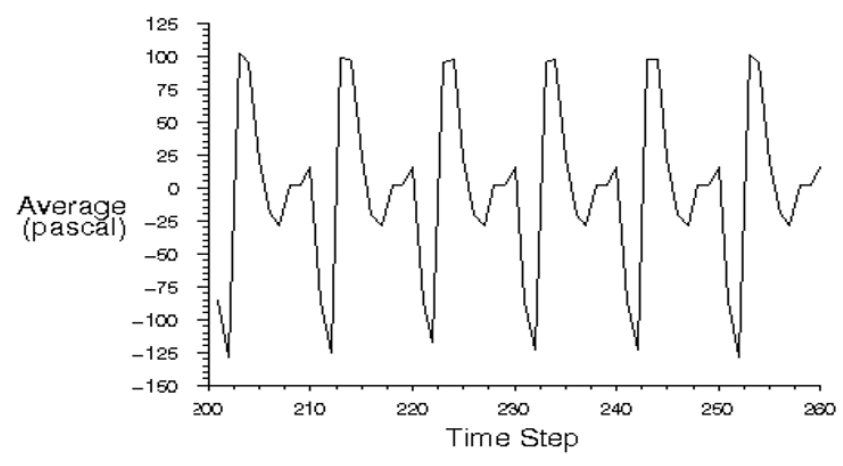

\section{Figure 5}

The pressure graph of the abdominal III aorta with $\mathbf{9 0 \%}$ aneurysm. The inlet pressure waive form of abdominal III aorta with $90 \%$ expansion rate of saccular aneurysm obtained by CFD method.

ent pressure graphs in the cardiovascular electronic system. The aortic aneurysm and the renal stenosis cause hypertension which is defined as increasing of blood pulse pressure.

\section{I) The aorta artery aneurysms}

The aorta aneurysm expansion rate is a function not only of initial size, but also of blood pressure. This indicates that increasing pulse pressure is associated with the aneurysm expansion rate [5]. Our resulting pressure drops in the present study agree with the results in Schurink's paper [3]. Our results, Table 2, show that pulse pressure increases with the rate of both aortic aneurysms including saccular and fusiform. Furthermore, clinical investiga-

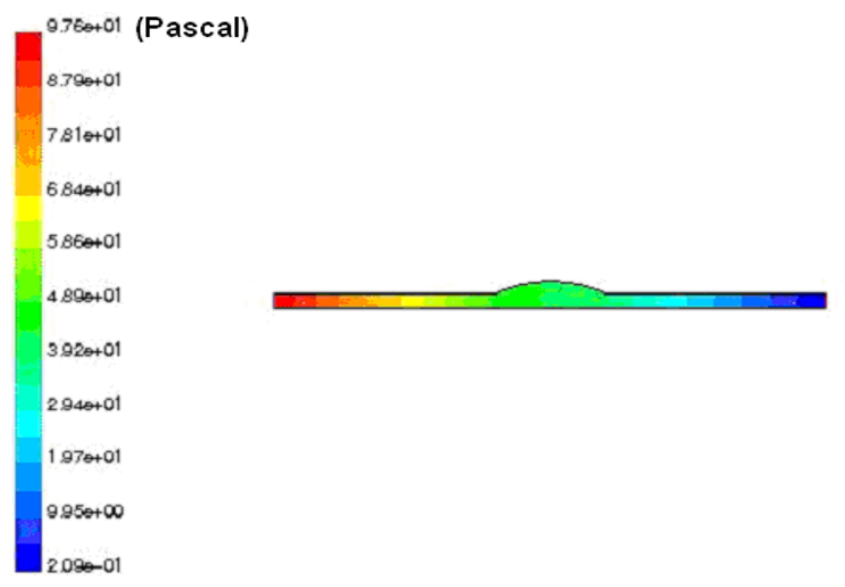

\section{Figure 6}

The pressure contour of the abdominal III aorta with $\mathbf{9 0 \%}$ aneurysm. The pressure contour of abdominal III aorta with $90 \%$ saccular aneurysm obtained by CFD method. The pressure(pascal) decreases along the artery length.

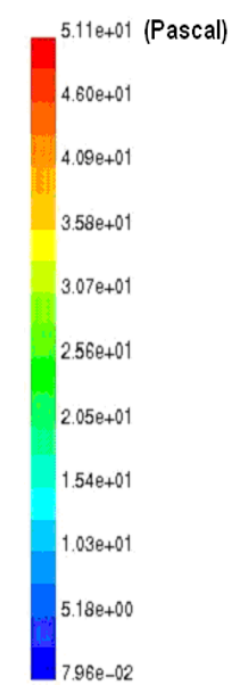

Figure 7

The pressure contour of the thoracic I aorta with $\mathbf{5 0} \%$ aneurysm. The pressure contour of abdominal III aorta with $90 \%$ fusiform aneurysm obtained by CFD method. The contour shows the variations of the pressure(pascal) along the artery.

tions demonstrate that $70-90 \%$ of patients with aortic aneurysms have high blood pressure [4] and supports the clinical importance of blood pressure control in reducing the risk of rupturing in the aortic aneurysms. On the other hand, the most effective factor which controls the hypertension of the aortic aneurysms is compliance [3]. Furthermore, alerted elastic properties and a reduced concentration of aortic elastic both have been associated with the aortic aneurysms [3]. In the present study, the compliance of the aorta artery increases with the rate of the aneurysms. The clinical investigations [4] imply that an increase in the compliance at the maximum aneurysm diameter was associated with rupture or need for surgery. We have shown that the higher aneurysm rate causes more hypertension and increasing of the pulse pressure in the cardiovascular system. The clinical data reported the pulse pressure of 52.5-120 mmHg for the aortic aneurysms depending on the rate of the aneurysms [15]. Our results were compared with these data and were in good agreement with them. We have found the average increase of 85 $\mathrm{mmHg}$ (volt) in the pulse pressure of the abdominal I aortic aneurysms. The values are $82 \mathrm{mmHg}$ for the abdominal II, $77 \mathrm{mmHg}$ for the thoracic I and $85 \mathrm{mmHg}$ for the thoracic II.

\section{2) The renal artery stenosis}

The previous studies [6-8] found a positive correlation between blood pulse pressure and the rate of renal stenosis and noted that the hypertension due to the stenosis 

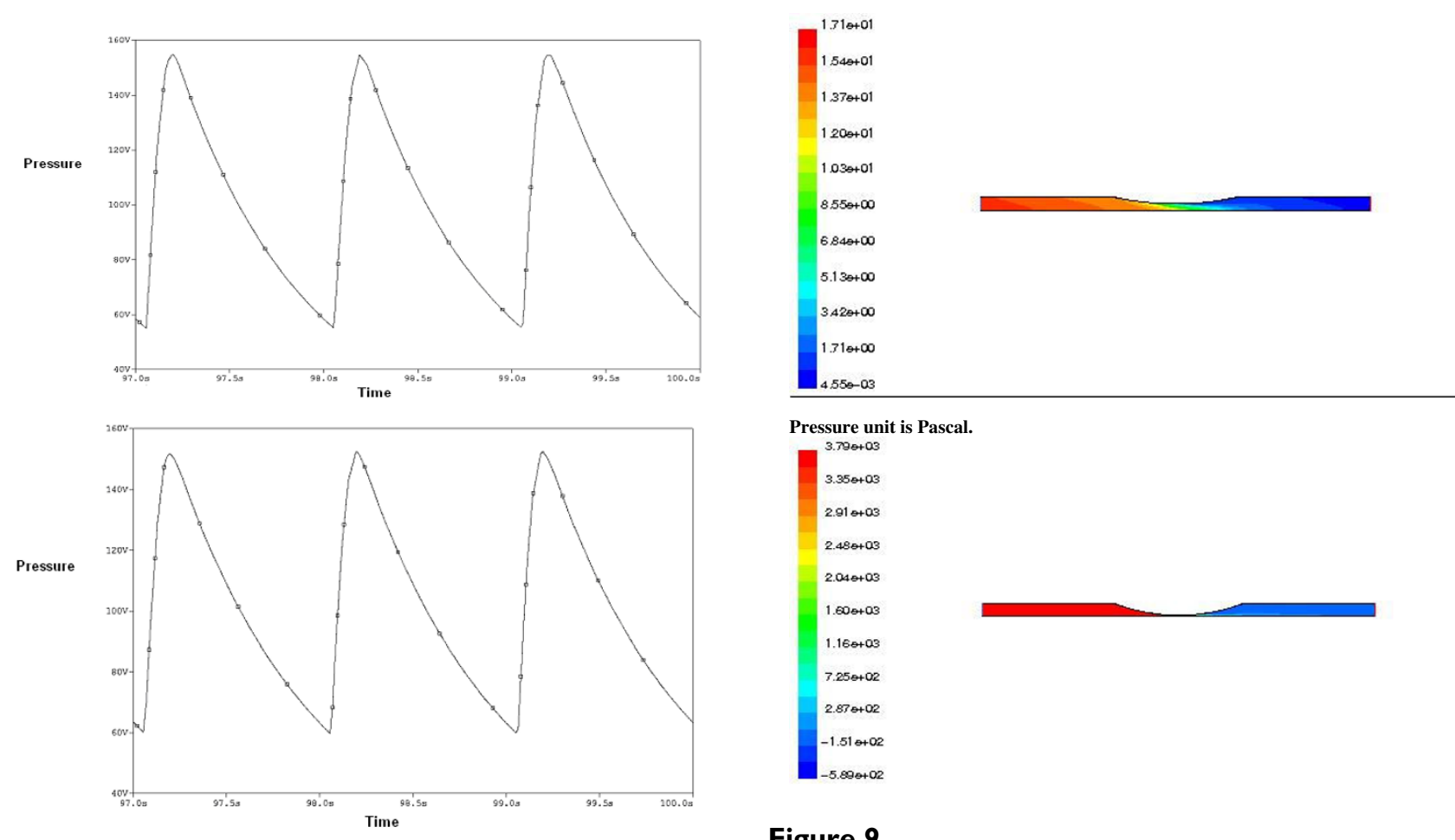

Figure 8

The electrcal pressure graphs of the abdominal I aorta with $20 \%$ saccular aneurysm(above) and abdominal II aorta with $\mathbf{4 0} \%$ fusiform aneu-

rysm(under). The pressure waive forms of the abdominal I aorta with the $20 \%$ saccular aneurysm(above) which obtained from the electrical circuit as well as abdominal II aorta with the $40 \%$ fusiform aneurysm(under).

depends to many genetic factors such as fibrillin. The investigations indicate that increasing pulse pressure is associated with the stenosis expansion rate which leads to hypertension [6]. The other clinical data [9] reported the renal systolic pressure to be $124-166 \mathrm{mmHg}$ and the diastolic to be $84-108 \mathrm{mmHg}$ due to the rate of the stenosis. Our modelling results, Table 3, report the significant increase in the pulse pressure due to the stenosis narrowing rate. These values have the average of $102 \mathrm{mmHg}$ (volt) for diastolic and $152 \mathrm{mmHg}$ (volt) for systolic. This

\section{Figure 9}

The pressure contours of the renal artery with $\mathbf{5 0 \%}$ (above) and $\mathbf{9 0 \%}$ stenosis (under). The pressure contour of the renal artery with $50 \%$ (above) and $90 \%$ (under) narrowing rate of stenosis obtained by CFD method. The high pressure (pascal) regions along the artery sections are at the inlet to the middle portion.

implies that the modelling results are in a good agreement with the clinical data.

\section{Conclusion}

In summary, our results indicate that expansion rate of the aortic aneurysms as well as the narrowing rate of the renal stenosis both are directly associated with hypertension, supporting the clinical importance of blood pressure control. We hereby stress that our model is an ideal and general model of the cardiovascular system. This electrical model proves useful for studying the pathogeneses of the cardiovascular system as discussed above.

Table 3: The results of modelling for the renal stenosis. The values of pressure drops (obtained by CFD), compliances (obtained by the mathematics) and final Diastolic/Systolic pressures of the renal with stenosis (obtained by electrical system). Please note that the values are approximate.

\begin{tabular}{lccc}
\hline Renal $(\mathrm{Dia}=2.6 \mathrm{~mm}, \mathrm{~L}=32 \mathrm{~mm})$ & $\Delta \mathrm{P}(\mathrm{Pa})$ Stenosis & $\mathrm{C}(\mathrm{ml} / \mathrm{Kpa})$ Stenosis & Diastol/Systole Pressure $(\mathrm{mmHg})$ \\
\hline $20 \%$ Stenosis & 7.46 & 0.01512 & $82-121$ \\
$50 \%$ Stenosis & 17.1 & 0.0236 & $85-127$ \\
$70 \%$ Stenosis & 75 & 0.116 & $97-148$ \\
$90 \%$ Stenosis & 3790 & 0.136 & $145-210$ \\
\hline
\end{tabular}




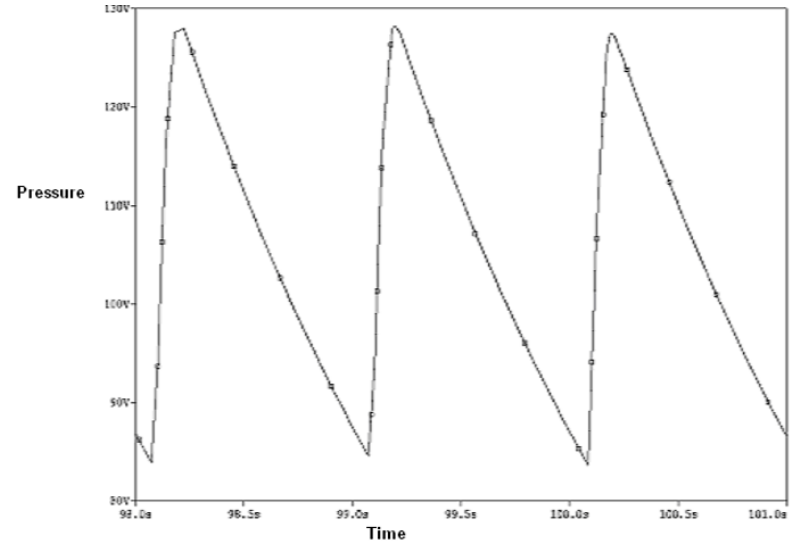

Figure 10

The electrcal pressure graph of the renal artery with the $50 \%$ stenosis. The pressure waive form of the renal artery with the $50 \%$ narrowing rate of stenosis which obtained from the electrical circuit.

\section{References}

I. Long A, Rouet L, Bissery A, Rossignol P, Mouradian D, Sapoval M: Compliance of abdominal aortic aneurysms: Evaluation of tissue Doppler imaging. Journal of ultrasound in medical and biology 2004, 30(9): I099-I I08.

2. Morris-Stiff G, Haynes M, Ogunbiyi S: Is assessment of popliteal artery diameter in patients undergoing screening for abdominal aortic aneurysms a world while procedure. European journal of vascular and endovascular surgery 2005, 30:71-74.

3. Schurink H, Baalen JM, Aars NJM: Experimental study of influence endoleak size on pressure in the aneurysm sac and the consequences. British journal of surgery 2000, 87(I):71-78.

4. Tilson MD, Charles DB: The abdominal aortic aneurysms. Annals the New York academy of science 1996, 800:.

5. Wilson K, Hoskins P, Lee A: Ultrasonic measurement of abdominal aortic aneurysm wall compliance: $A$ reproducibility study. European journal of vascular and endovascular surgery 2000, 3 I(3):507-5I3.

6. Woolfson RG: Renal artery stenosis : Diagnosis and management. Indian journal of heart 2003, 54:26 I-265.

7. Bude OR, Forauer RA: Is it necessary to study accessory arteries when screening the renal arteries for renovascular hypertension? Journal of radiology 2003, 226(2):4 I I-4 I6.

8. Renal Artery Stenosis/Renovascular Hypertension [http:// www.emedicine.com/radio/topic600.htm]

9. Coen G, Calabria S, Lai S: Atherosclerotic ischemic renal. Diagnosis and prevalence in an hypertensive and/or uremic elderly population. BMC Nephrology 2003, 4:2.

10. Hassani K, Navidbakhsh, Rostami R: Simulation of cardiovascular system using equivalent electronic system. Journal of Biomedical papers 2006, I50(I): I05-II2.

I I. Wang J], Parker KH: Wave propagation in a model of the arterial circulation. Journal of Biomechanics 2004, 37:457-70.

12. Hassani K: Simulation of the cardiovascular system and study of the pathologies. In $\mathrm{PhD}$ thesis Amirkabir University, Biomedical Engineering Department; 2006.

13. Navidbakhsh M: Numerical simulation of blood flow in human artery system. In PhD thesis I.N.P.L Luran polytechnic, France; 1996.

14. Rideout VC: Mathematical and computer modelling of physiological systems New York: Prentice Hall; 1991.

15. Wilson K, Lindholt J, Hoskins P: The relationship between abdominal aortic aneurysm distensibility and serum markers of elastin and collagen metabolism. European journal of vascular and endovascular surgery 2001, 2 I(2): I75-178.

16. Guyton AC: Text book of physiology Volume I. Philadelphia : W.B.Saunders; 1996.
17. Kaya A, Heijmen HR, Overtoom TT, Vos JA, Morshuis WJ, Schepens MA: Thoracic stent grafting for acute aortic pathology. The Annals of thoracic surgery 2006, 82(2):560-565.

18. Alkhunaizi A, Chapman A: Renal artery stenosis and unilateral focal and segmental glomerulosclerosis. Am J Kidney Dis 1997, 29:936-94I.

19. Gao F, Watanabe M, Matsuzawa T: Stress analysis in a layered aortic arch model under pulsatile blood flow. Biomedical engineering online journal 2006, 5:25.

20. Pralhad RN, Schultz DH: Modeling of arterial stenosis and its applications to blood diseases. Journal of mathematical biosciences 2004, I 90(2):203-230.

\section{Publish with Biomed Central and every scientist can read your work free of charge}

"BioMed Central will be the most significant development for disseminating the results of biomedical research in our lifetime. "

Sir Paul Nurse, Cancer Research UK

Your research papers will be:

- available free of charge to the entire biomedical community

- peer reviewed and published immediately upon acceptance

- cited in PubMed and archived on PubMed Central

- yours - you keep the copyright

Submit your manuscript here:

http://www.biomedcentral.com/info/publishing_adv.asp
BiolMedcentral 